\title{
Compatibilidade entre a inoculação de rizóbios e fungicidas aplicados em sementes de feijoeiro-comum
}

\author{
Maurício Rocha Kintschev ${ }^{1}$, Augusto César Pereira Goulart ${ }^{2}$, Fábio Martins Mercante ${ }^{2 *}$
}

\begin{abstract}
${ }^{1}$ Mestrando, Universidade Estadual do Mato Grosso do Sul, Rod. Aquidauana/UEMS, km 12, Caixa Postal 25, 79200-000, Aquidauana, MS, mauricioagro2010@gmail.com; ${ }^{2}$ Pesquisador, Embrapa Agropecuária Oeste, Caixa Postal 449, 79804-970, Dourados, MS, augusto.goulart@ embrapa.br. *Bolsista de Produtividade em Pesquisa do CNPq.

Autor para correspondência: Fábio Martins Mercante (fabio.mercante@embrapa.br)

Data de chegada: 10/07/2013. Aceito para publicação em: 15/10/2014.
\end{abstract}

$10.1590 / 0100-5405 / 1906$

\section{RESUMO}

Kintschev, M.R.; Goulart, A.C.P.; Mercante, F.M. Compatibilidade entre a inoculação de rizóbios e fungicidas aplicados em sementes de feijoeirocomum. Summa Phytopathologica, v.40, n.4, p.338-346, 2014.

O objetivo do presente estudo foi avaliar os efeitos do tratamento de sementes de feijoeiro com diferentes fungicidas na sobrevivência de estirpe de Rhizobium tropici (SEMIA 4077) e Rhizobium freirei (SEMIA 4080), na nodulação das plantas e na produtividade da cultura. Foram conduzidos dois ensaios em substrato esterilizado, sob condições de casa de vegetação e um ensaio no campo experimental da Embrapa Agropecuária Oeste, em Dourados, MS, num Latossolo Vermelho distroférrico típico. Os fungicidas (princípios ativos) utilizados nos ensaios foram: (1) carbendazim + tiram (Produto A); (2) carbendazim + tiram (Produto B); (3) carboxin + tiram; (4) fludioxonil + metalaxil-M; (5) fludioxonil + metalaxil-M + tiabendazol; (6) fluazinam + tiofanato metílico; (7) fipronil + tiofanato metílico + piraclostrobina; (8) clorotalonil + tiofanato metílico. A sobrevivência das estirpes de $R$. tropici inoculadas nas sementes de feijoeiro foi afetada pela aplicação dos fungicidas, principalmente por aqueles com modo de ação de contato. Observou-se ainda, com a aplicação dos fungicidas, redução na nodulação das plantas de feijoeiro, especialmente da massa nodular, tanto nos ensaios conduzidos em substrato esterilizado, em casa de vegetação, quanto no experimento a campo, onde também observou-se redução na produtividade do feijoeiro pela aplicação da maioria dos fungicidas avaliados. Os fungicidas que mais afetaram o rendimento de grãos foram carbendazim + tiram (Produto B) e carboxin + tiram. Os produtos fipronil + tiofanato metílico + piraclostrobina, fludioxonil + metalaxil-M + tiabendazol e fludioxonil + metalaxil-M não afetaram a produtividade da cultura, embora a massa seca de nódulos tenha sido reduzida em todos os ensaios.

Palavras-chave adicionais: fixação biológica de nitrogênio, nodulação.

\section{ABSTRACT}

Kintschev, M.R.; Goulart, A.C.P.; Mercante, F.M. Compatibility between rhizobium inoculation and fungicide application in seeds of common beans. Summa Phytopathologica, v.40, n.4, p.338-346, 2014.

The aim of this study was to evaluate the effects of treatment of common bean seeds with different fungicides on the survival of strains of Rhizobium tropici (SEMIA 4077) and Rhizobium freirei (SEMIA 4080), as well as on plant nodulation and on crop yield. Two experiments were carried out in sterilized substrate, under greenhouse conditions and in the experimental field of Embrapa Western Agriculture, in Dourados, Mato Grosso do Sul State, in a typical Oxisol. The fungicides (active ingredients) used in the experiments were: (1) carbendazim + thiram (Product A), (2) carbendazim + thiram (Product B), (3) carboxin + thiram, (4) fludioxonil + metalaxyl-M, (5) fludioxonil + metalaxyl-M + thiabendazole, (6) fluazinam + methyl thiophanate, (7) fipronil + methyl thiophanate + pyraclostrobin, (8) chlorothalonil + methyl thiophanate. The survival of $R$. tropici strains inoculated in bean seeds was affected by the application of fungicides, especially contact fungicides. In addition, fungicide application led to a reduction in the nodulation of bean plants, especially for nodular mass, either in assays carried out on sterilized substrate, in a greenhouse, or in the field experiment, where grain yield reduction was also noted with the use of most evaluated fungicides. The fungicides that mostly affected grain yield were carbendazim + thiram (Product B) and carboxin + thiram. The products fipronil + thiophanate methyl + pyraclostrobin, fludioxonil + metalaxyl-M + thiabendazole and fludioxonil + metalaxyl-M did not affect the crop yield, although the dry weight of nodules was reduced in all trials.

Additional keywords: biological nitrogen fixation, nodulation

O feijoeiro-comum (Phaseolus vulgaris L.) é uma leguminosa cultivada em todas as regiões brasileiras e, na safra 2011/12, obteve rendimento médio de $894 \mathrm{~kg} \mathrm{ha}^{-1}$. No Estado de Mato Grosso do Sul, nesta mesma safra, o rendimento médio foi de $1.262 \mathrm{~kg} \mathrm{ha}^{-1}$ (13). A sua grande importância social e econômica no País é evidenciada por representar a principal fonte proteica na dieta alimentar da população mais pobre e pelo contingente de pequenos agricultores envolvidos na sua produção, geralmente, utilizando baixo nível tecnológico. Contudo, nas últimas décadas, tem sido verificado um crescente interesse de produtores de outros segmentos do agronegócio que adotam 
níveis tecnológicos mais elevados, incluindo a irrigação e a colheita mecanizada (44).

Entre os fatores mais limitantes da produtividade da cultura do feijoeiro, destaca-se a baixa fertilidade dos solos tropicais, que limita a nutrição das plantas $(5,41)$. Considerando que o nitrogênio é um dos nutrientes requeridos em maiores quantidades pelo feijoeiro e os solos tropicais são, em geral, pobres neste nutriente, o seu suprimento adequado torna-se de fundamental importância para a obtenção de maiores rendimentos nesta cultura. Tem sido verificado que os teores máximos de nitrogênio nos solos tropicais estão em torno de $0,3 \%$, sendo rapidamente esgotado após poucos ciclos de cultivo, caso não haja reposição (40).

As principais fontes de fornecimento de $\mathrm{N}$ à cultura são os fertilizantes nitrogenados e o processo de fixação biológica de nitrogênio atmosférico (FBN), por meio da simbiose do feijoeiro com bactérias do grupo dos rizóbios. Neste contexto, tem sido verificado que a aplicação de adubo mineral nitrogenado nos solos tropicais tem resultado, muitas vezes, em baixa frequência de resposta pela cultura do feijoeiro (42). Esta falta de resposta à adubação nitrogenada tem sido atribuída à sua baixa eficiência de utilização (inferior a 50\%) pelas plantas, decorrente das perdas por lixiviação, volatilização e desnitrificação $(15,21)$. Além disso, deve-se considerar o elevado custo econômico dos adubos nitrogenados e os problemas ambientais que podem ocorrer com estas perdas, como o acúmulo de formas nitrogenadas, particularmente nitrato $\left(\mathrm{NO}^{-3}\right)$, nas águas de rios, lagos e aquíferos subterrâneos, atingindo níveis tóxicos aos peixes e ao homem, e a degradação da camada de ozônio, agravando o efeito estufa, pela liberação de formas gasosas, como $\mathrm{N}_{2} \mathrm{O}$ (óxido nitroso) e NO (óxido nítrico).

Por outro lado, tem sido verificado que o fornecimento de nitrogênio, por meio do processo de FBN, pode aumentar a produtividade média nacional de feijoeiro sem o uso de adubos nitrogenados, alcançando patamares de produtividade acima de $2.500 \mathrm{~kg} \mathrm{ha}^{-1}(19,33)$. Além disso, a FBN influencia positivamente a qualidade do solo, por evitar todos os problemas relacionados à poluição causada pelos adubos nitrogenados (22). Entretanto, diversos fatores podem limitar a simbiose entre estirpes de rizóbio e o feijoeiro, destacando-se a acidez do solo, $\mathrm{pH}$ baixo, concentrações elevadas de $\mathrm{Al}$ tóxico e temperaturas elevadas $(25,26)$.

Dentre os outros fatores limitantes à produção do feijoeiro, as doenças contribuem com uma parcela significativa para o insucesso da cultura, diminuindo o rendimento e depreciando a qualidade do produto $(17,38)$. A maioria das doenças de importância econômica que ocorre no feijoeiro é causada por patógenos que são transmitidos pelas sementes $(18,29,37)$. Isso implica na introdução de doenças em áreas novas ou mesmo a reintrodução em áreas cultivadas nas quais a doença já tenha ocorrido e, em função da adoção de práticas eficientes de controle, como, por exemplo, a rotação de culturas, ficaram livres da mesma. A maneira mais econômica e eficaz de controlar estes fungos transmitidos pelas sementes, bem como os de solo, é por meio do tratamento das sementes de feijoeiro com fungicidas $(11,18,23)$. Dentre patógenos alvo do tratamento de sementes com fungicidas, destacam-se Rhizoctonia solani, Sclerotinia sclerotiorum, Fusarium spp., Aspergillus flavus, Colletotrichum lindemuthianum e Phaeisariopsis griseola (18).

Contudo, tem sido mencionado que a aplicação de determinados fungicidas no tratamento de sementes de leguminosas, como feijoeiro (3), soja (9) e alfafa (31), podem ocasionar uma redução na população de bactérias diazotróficas utilizadas nos inoculantes microbianos. Resultados experimentais obtidos por Araújo \& Araújo (3) demonstraram que a sobrevivência do rizóbio inoculado nas sementes de feijoeiro foi prejudicada pela aplicação de fungicidas (benomyl, captan, carboxim, tiram, PCNB e carboxim + tiram), e consequentemente, a nodulação das plantas foi reduzida. O mesmo foi constatado por Ramos e Ribeiro Jr. (35), que observaram, duas horas após o contato com os fungicidas, as estirpes CIAT 652 e CPAC 1135 de rizóbio tiveram uma significativa redução no número de células quando comparadas com o tratamento sem fungicida. Nestes estudos, os fungicidas benomil, etridiazol e tiofanato-metil tiveram os maiores efeitos na sobrevivência das estirpes de rizóbio.

Contudo, os efeitos de toxicidade dos fungicidas são variáveis, dependendo do produto e da estirpe de rizóbio inoculada, tornando-se indispensável a avaliação da compatibilidade dos fungicidas atualmente recomendados comercialmente para tratamento de sementes e das estirpes de rizóbio recomendadas para inoculação, de modo a garantir os patamares mais elevados de FBN, a sanidade das sementes e, consequentemente, incrementos na produtividade de grãos do feijoeiro.

O objetivo deste trabalho foi avaliar a compatibilidade entre a inoculação de estirpes de $R$. tropici e $R$. freirei e os fungicidas recomendados para o tratamento de sementes de feijoeiro, seus efeitos na sobrevivência do rizóbio, na nodulação e na produtividade da cultura.

\section{MATERIAL E MÉTODOS}

Os estudos foram conduzidos em laboratório, sob condições controladas de casa de vegetação e no campo experimental da Embrapa Agropecuária Oeste, em Dourados, MS. Em todos os ensaios, utilizaram-se sementes de feijoeiro (Phaseolus vulgaris L.), cultivar Pérola, pertencente ao grupo comercial Carioca, com ciclo de 90 a 100 dias, de porte semi-ereto. Foi utilizado inoculante turfoso contendo a mistura das estirpes SEMIA 4077 (= CIAT 899) de Rhizobium tropici e SEMIA 4080 (= PRF 81) de Rhizobium freirei, recomendadas comercialmente no Brasil. O inoculante foi produzido na Embrapa Cerrados, na concentração de $6 \times 10^{9}$ células $\mathrm{g}^{-1}$ de inoculante turfoso, sendo aplicado na dose de $1 \mathrm{~kg} 50 \mathrm{~kg}^{-1}$ de sementes, utilizando como adesivo, solução açucarada, a 10\%. A inoculação dos rizóbios nas sementes foi realizada após a aplicação dos fungicidas, conforme a recomendação técnica.

Os fungicidas utilizados nos ensaios correspondem aos seguintes princípios ativos: 1) carbendazim + tiram (produto A); 2) carbendazim +tiram (produto B); 3) carboxin + tiram; 4) fludioxonil + metalaxil-M; 5) fludioxonil + metalaxil-M + tiabendazol; 6) fluazinam + tiofanato metílico; 7) fipronil + tiofanato metílico + piraclostrobina; 8) clorotalonil + tiofanato metílico. As doses dos produtos utilizados e os respectivos ingredientes ativos estão relacionados na Tabela 1 .

Três tratamentos adicionais foram incluídos nas avaliações, para comparação, sendo um com a mistura das estirpes SEMIA 4077 (= CIAT 899) de $R$. tropici e SEMIA 4080 (= PRF 81) de $R$. freirei e dois sem adição de inoculante (com e sem adubação mineral nitrogenada).

\section{Sobrevivência de rizóbios em sementes de feijoeiro}

As avaliações da estimativa do número de células de rizóbio nas sementes de feijoeiro tratadas com os fungicidas e inoculadas com a mistura das estirpes SEMIA 4077 e SEMIA 4080 foram realizadas pelo método do número mais provável (NMP), diluição e infecção em plantas (processo indireto), utilizando-se a tabela adaptada de Andrade \& Hamakawa (2).

Inicialmente, retirou-se uma amostra de $10 \mathrm{~g}$ das sementes de feijoeiro, tratadas com os diferentes fungicidas (Tabela 1), e inoculadas com a mistura das estirpes SEMIA 4077 + SEMIA 4080. Em seguida, as sementes foram colocadas em erlenmeyers contendo $90 \mathrm{~mL}$ de água 
Tabela 1. Doses dos produtos utilizados, respectivos ingredientes ativos e modo de ação dos fungicidas.

\begin{tabular}{lcccc}
\hline & Nome comum & Dose (mL/50kg de sementes) & Ingrediente ativo (g) & Modo de ação \\
\hline 1 & Carbendazim + Tiram (Produto A) & 200 & $15+35$ & Contato/ sistêmico \\
2 & Carbendazim + Tiram (Produto B) & 200 & $15+35$ & Contato/ sistêmico \\
3 & Carboxin + Tiram & 250 & $20+20$ & Contato/ sistêmico \\
4 & Fludioxonil + Metalaxil-M & 100 & $2,5+1$ & Contato/ sistêmico \\
5 & Fludioxonil + Metalaxil-M + Tiabendazol & 100 & $2,5+2+15$ & Contato/ sistêmico \\
6 & Fluazinam + Tiofanato metílico & 180 & $5,25+35$ & Contato/ sistêmico \\
7 & Fipronil + Tiofanato metílico + & 200 & $25+22,5+2,5$ & Contato/ sistêmico \\
8 & Clorotalonil + Tiofanato metílico & 300 & $50+20$ & Contato/ sistêmico \\
\hline
\end{tabular}

destilada esterilizada, sendo adicionados $300 \mu \mathrm{L}$ de Tween 80 , sob agitação (200 rpm), por 30 minutos. Após a agitação, foram realizadas diluições decimais, sendo utilizadas as concentrações $10^{-3}, 10^{-4}$ e $10^{-5}$ nas avaliações realizadas em casa de vegetação. Neste ensaio, foram utilizados vasos de $500 \mathrm{~mL}$ contendo substrato (areia + vermiculita, 1:1 - v:v) esterilizado, onde cada semente de feijoeiro recebeu a inoculação com $0,5 \mathrm{~mL}$ das mesmas diluições utilizadas na contagem de células $\left(10^{-3}, 10^{-4}\right.$ e $\left.10^{-5}\right)$. Inicialmente, foram utilizadas quatro sementes por vaso e, aos 15 dias após a emergência das plantas (DAE), realizou-se o desbaste, deixando-se duas plantas em cada vaso. As avaliações de presença e ausência de nódulos nas plantas inoculadas foram realizadas aos 21 dias após a semeadura, e cada planta foi referida como positiva (sucesso), com ocorrência de um ou mais nódulos, e negativa (insucesso), quando nenhum nódulo foi formado. A partir dos resultados positivos ou negativos em cada uma das diluições das suspensões inoculadas, foi estimado, na acepção matemática, o número de células viáveis de rizóbio na amostra (20). Esses valores foram encontrados na tabela adaptada de Andrade \& Hamakawa (2). O delineamento experimental utilizado foi em blocos casualizados, com três repetições para cada diluição.

\section{Ensaios em casa de vegetação}

Foram conduzidos dois ensaios sob condições controladas de casa de vegetação, sendo utilizados vasos de Leonard (Vincent, 1970) e vasos de $500 \mathrm{~mL}$, contendo substrato (areia + vermiculita, 1:1 - v:v) esterilizado, onde foram semeadas quatro sementes de feijoeiro, cv. Pérola, por vaso. Aos 15 dias após a emergência das plantas, foi realizado o desbaste, deixando-se duas plantas por vaso.

As sementes foram previamente tratadas com diferentes fungicidas (Tabela 1) e inoculadas com rizóbio (CIAT 899 e PRF 81). Nos tratamentos utilizados como controle (testemunhas absoluta e nitrogenada, com aplicação de $20 \mathrm{mg}$ de $\mathrm{N}_{\text {planta }}{ }^{-1}$ semanalmente), sem aplicação de fungicidas e inoculante, as sementes foram previamente esterilizadas superficialmente, sendo tratadas com álcool absoluto por 30 segundos e, em seguida, imersas em hipoclorito de sódio (10\%), por 3 minutos, e lavadas dez vezes com água destilada esterilizada (43).

Durante o período de crescimento, as plantas foram supridas com solução nutritiva sem nitrogênio (30).

A coleta das plantas foi realizada aos $45 \mathrm{DAE}$, separando-se a parte aérea do sistema radicular. Foram realizadas as seguintes avaliações: número de nódulos, matéria seca de nódulos e das raízes, com secagem em estufa a $60^{\circ} \mathrm{C}$, até atingirem peso constante, além do teores de nitrogênio total da parte aérea, determinados pelo método de Kjeldahl (semi-micro), segundo Malavolta et al. (24).
Em ambos os ensaios, o delineamento experimental utilizado foi em blocos casualizados, com cinco repetições. Os dados coletados foram submetidos à análise de variância, a $5 \%$ de probabilidade $(\mathrm{P}<$ $0,05)$ e, quando significativas, as médias foram comparadas pelo teste de Tukey $(\mathrm{P}<0,01)$. Essas análises foram realizadas com o auxílio do aplicativo estatístico ASSISTAT (39).

\section{Ensaio conduzido a campo}

O experimento foi conduzido no campo experimental da Embrapa Agropecuária Oeste, em Dourados, MS, num Latossolo Vermelho distroférrico típico, localizado na latitude $22^{\circ} 14^{`} \mathrm{~S}$ e longitude de $54^{\circ} 49^{\prime}$ $\mathrm{W}$, com altitude de $450 \mathrm{~m}$, no período de março a junho de 2012. O clima da região é classificado como Cwa, mesotérmico úmido, com verão quente e inverno seco (Amaral et al., 2000). A análise química do solo mostrou os seguintes valores: $\mathrm{pH}{\left(\mathrm{CaCl}^{2}\right)}=5,3$; M.O. $=31,45 \mathrm{~g}$ $\mathrm{kg}^{-1} ; \mathrm{P}-$ mehlich $=25,9 \mathrm{mg} \mathrm{dm}{ }^{-3} ; \mathrm{K}^{+}=0,65 \mathrm{cmol} \mathrm{dm}_{\mathrm{c}}^{-3} ; \mathrm{Ca}^{++}=5,1 \mathrm{cmol}_{\mathrm{c}}$ $\mathrm{dm}^{-3} ; \mathrm{Mg}^{++}=1,8 \mathrm{cmol}_{\mathrm{c}} \mathrm{dm}^{-3} ; \mathrm{H}+\mathrm{Al}=4,9 \mathrm{cmol}_{\mathrm{c}} \mathrm{dm}^{-3} ; \mathrm{CTC}=12,5 \mathrm{cmol}_{\mathrm{c}}$ $\mathrm{dm}^{-3}$ e os micronutrientes $\mathrm{Fe}=24,9 \mathrm{mg} \mathrm{dm}^{-3} ; \mathrm{Cu}=11,2 \mathrm{mg} \mathrm{dm}^{-3} ; \mathrm{Mn}^{\mathrm{c}}$ $=53,0 \mathrm{mg} \mathrm{dm}^{-3} ;$ e $\mathrm{Zn}=2,2 \mathrm{mg} \mathrm{dm}^{-3}$.

$\mathrm{O}$ ensaio consistiu dos mesmos tratamentos utilizados nos ensaios em casa de vegetação, sendo realizadas avaliações da nodulação (número e matéria seca de nódulos), matéria seca da parte aérea, teores de nitrogênio total da parte aérea e rendimento de grãos do feijoeiro. Para a avaliação de produtividade, os grãos colhidos na área útil de cada parcela foram beneficiados e a umidade corrigida para $13 \%$. As demais características foram avaliadas conforme descrito nos ensaios realizados em casa de vegetação.

Cada parcela experimental foi constituída por quatro linhas com quatro metros de comprimento, espaçadas com $0,50 \mathrm{~m}$, perfazendo $8 \mathrm{~m}^{2}$ ( $2 \mathrm{~m} \mathrm{x} 4 \mathrm{~m}$ ) de área total, ajustando a população final para 15 plantas/ metro. A área útil da parcela foi constituída pelas duas linhas centrais, descartando 0,50 m de cada extremidade. A adubação básica de plantio constou da aplicação de $300 \mathrm{~kg} \mathrm{ha}^{-1}$ da formulação 00-18-18 (N-P-K). A adubação nitrogenada nas parcelas correspondentes ao controle nitrogenado foi de $80 \mathrm{~kg} \mathrm{ha}^{-1}$, sendo $50 \%$ aplicados na semeadura e $50 \%$ em cobertura, aos 38 DAE. A semeadura foi realizada no dia 13/03/2012, manualmente, e a avaliação da nodulação foi efetuada aos 38 DAE.

O delineamento experimental utilizado foi o de blocos ao acaso, com cinco repetições. Os dados coletados foram submetidos à análise de variância, a 5\% de probabilidade, e, quando significativas, as médias foram comparadas pelo teste de Tukey, ao nível de $1 \%$ de probabilidade. Essas análises foram realizadas com o auxílio do aplicativo estatístico ASSISTAT (39). 


\section{RESULTADOS E DISCUSSÃO}

\section{Sobrevivência de rizóbios em sementes de feijoeiro}

Os resultados de infectividade dos rizóbios inoculados em plantas de feijoeiro, utilizando-se as diluições $10^{-3}, 10^{-4}$ e $10^{-5}$, demonstraram que os fungicidas avaliados afetaram a sobrevivência das bactérias fixadoras de nitrogênio até a diluição $10^{-5}$, uma vez que a concentração de células de rizóbio $\mathrm{mL}^{-1}$ diminuíram em comparação ao tratamento com a inoculação padrão (IP), sem uso de fungicida.

Os fungicidas contendo os princípios ativos fipronil + tiofanato metílico + piraclostrobina e clorotalonil + tiofanato metílico foram os que menos afetaram a sobrevivência dos rizóbios, propiciando uma concentração de células maior que os demais tratamentos que receberam aplicação de fungicidas (Tabela 2). Por outro lado, o tratamento com aplicação do fungicida com os princípios ativos fluazinam + tiofanato metílico foi o mais prejudicial à sobrevivência das bactérias inoculadas nas sementes, proporcionando a maior redução no número de células, em comparação aos demais tratamentos com fungicidas (Tabela 2). Contudo, salienta-se que os fungicidas com os princípios ativos de contato, quando em maior proporção que os sistêmicos, foram os que propiciaram a maior redução de células de rizóbio quando aplicados nas sementes; a exceção foi verificada com a aplicação do fungicida com os princípios ativos fluazinam + tiofanato metílico, que possui um modo de ação predominantemente sistêmico, e foi o produto mais prejudicial à sobrevivência das bactérias inoculadas (Tabela 2).

Deve-se destacar ainda que dois produtos comerciais com os mesmos princípios ativos (carbendazim + tiram) afetaram, em intensidade diferente, a sobrevivência das bactérias nas sementes de feijoeiro, indicando que o efeito de fitotoxicidade pode não estar relacionado exclusivamente aos princípios ativos dos fungicidas, mas a algum componente do veículo do produto.

Estudos realizados por Araújo \& Araújo (3), em laboratório, utilizando o método de diluição e contagem direta em placas (método de espalhamento), demonstraram que a sobrevivência da estirpe CIAT 899 de $R$. tropici inoculada foi afetada negativamente por todos os fungicidas utilizados no tratamento das sementes, sendo que os fungicidas mais prejudiciais ao rizóbio inoculado nas sementes foram carboxin + tiram e benomyl. Ramos \& Ribeiro Jr. (35) verificaram que os fungicidas benomil e truban tiveram os maiores efeitos negativos na sobrevivência das estirpes de rizóbio inoculadas em sementes de feijoeiro. Resultados obtidos por Mercante et al. (27) demonstraram que a sobrevivência das estirpes SEMIA 5079 e SEMIA 5080 de $B$. japonicum, inoculadas em sementes de soja, foi afetada negativamente pela aplicação dos fungicidas carboxin + tiram, carbendazin + tiram (Produto A), carbendazin + tiram (Produto B), fludioxonil + metalaxil-M, após 48 horas de contato com o inoculante. Estudos realizados por Campo et al. (9), com a cultura da soja, demonstraram, em condições laboratoriais, que os fungicidas podem causar até $62 \%$ de mortalidade das bactérias inoculadas, duas horas após o tratamento das sementes, atingindo $95 \%$ após 24 horas.

\section{Ensaios conduzidos em casa de vegetação}

No primeiro experimento em casa de vegetação, conduzido em vasos de Leonard, os resultados mostraram que todos os fungicidas utilizados no tratamento de sementes de feijoeiro associado à inoculação das estirpes de $R$. tropici e $R$. freirei diferiram significativamente do tratamento onde houve apenas a inoculação, promovendo uma redução na nodulação (número e matéria seca de nódulos). As reduções ocasionadas pela utilização dos fungicidas no tratamento de sementes chegaram a $45 \%$, para o número de nódulos, quando as plantas de feijoeiro foram tratadas com carbendazim + tiram (Produto A). Já o tratamento com o fungicida carboxin + tiram chegou a reduzir em $46 \%$ a produção de matéria seca de nódulos (Tabela 3). Costa et al. (14), avaliando a sobrevivência de $B$. japonicum em sementes de soja tratadas com fungicidas, verificaram uma redução no número de nódulos de $48 \%$ em plantas de soja, quando as sementes foram tratadas com o fungicida carbendazin + tiram (Produto A), em comparação com as plantas apenas inoculadas. Do mesmo modo, resultados obtidos por Campo \& Hungria (8), em experimento conduzido no campo, mostraram que, dentre os fungicidas avaliados na cultura da soja, os menos tóxicos foram carboxin + tiram e difenoconazole + tiram, causando reduções de $39 \%$ e $43 \%$ no número e matéria seca de nódulos, respectivamente.

Os fungicidas com os princípios ativos carbendazim + tiram (produtos A e B), carboxim + tiram e fludioxonil + metalaxil-M +

Tabela 2. Efeito da aplicação de fungicidas em sementes de feijoeiro sobre a nodulação das plantas, realizada em condições de casa de vegetação, utilizando-se estirpes de Rhizobium tropici e Rhizobium freirei em três concentrações distintas $\left(10^{-3}, 10^{-4} \mathrm{e} 10^{-5}\right)$, por meio do método de diluição e infecção em plantas (processo indireto).

\begin{tabular}{ccc}
\hline Tratamentos & Fator NMP & $\begin{array}{c}\mathrm{N}^{\circ} \text { de células de } \\
\text { R. tropici } \mathrm{mL}^{-1}\end{array}$ \\
\hline Carbendazim + tiram (Produto A) + IP* & 0,620 & $0,77 \times 10^{5}$ \\
Carbendazim + tiram (Produto B) + IP & 1,568 & $1,72 \times 10^{5}$ \\
Carboxin + tiram + IP & 1,118 & $1,07 \times 10^{5}$ \\
Fludioxonil + metalaxil-M + IP & 1,098 & $1,09 \times 10^{5}$ \\
Fludioxonil + metalaxil-M + tiabendazol + IP & 2,046 & $2,13 \times 10^{5}$ \\
Fluazinam + tiofanato metílico + IP & 0,357 & $0,25 \times 10^{5}$ \\
Fipronil + tiofanato metílico + piraclostrobina + IP & 4,272 & $4,27 \times 10^{5}$ \\
Clorotalonil + tiofanato metílico + IP & 4,272 & $4,27 \times 10^{5}$ \\
IP & 9,324 & $4,83 \times 10^{5}$ \\
Controle sem N & - & 0 \\
Controle com N & - & 0 \\
\hline
\end{tabular}

*IP= inoculação padrão. Inoculante turfoso, contendo $10^{9}$ células de rizóbio/g de inoculante, aplicado na dose de $1 \mathrm{~kg}^{2} 50 \mathrm{~kg}^{-1} \mathrm{de}$ sementes, utilizando solução açucarada a $10 \%$ como adesivo. $\mathrm{NMP}=$ número mais provável. 
tiabendazol foram os que mais afetaram a produção de matéria seca da parte aérea, com reduções que variaram de $29 \%$ a $39 \%$. Os fungicidas com os demais princípios ativos mostraram-se similares $(\mathrm{p}<0,01)$ ao tratamento que recebeu apenas a inoculação com rizóbio (Tabela 3).

De modo geral, todos os fungicidas ocasionaram redução nos teores de $\mathrm{N}$ total da parte aérea das plantas de feijoeiro, variando entre $1 \% \mathrm{e}$ $27 \%$. As exceções foram verificadas com os fungicidas carbendazim + tiram (Produto B) e carboxin + tiram, que apresentaram teores de $\mathrm{N}$ total da parte aérea similares $(\mathrm{p}<0,01)$ aos verificados nas plantas que receberam apenas a inoculação de rizóbio, sem o tratamento de fungicidas nas sementes (Tabela 3). Os resultados foram similares aos encontrados por Cattelan et al. (12), que avaliaram na cultura da soja, sob condições de casa de vegetação, os efeitos dos fungicidas carboxin + tiram e tiram + tiabendazol, sobre estirpes de Bradyrhizobium, e não observaram redução no número de nódulos, matéria seca de nódulos (nodulação) e teor de N, quando comparados ao inoculante padrão. Estes resultados contrastam com aqueles obtidos por Bigaton et al. (7), na cultura da soja, em experimento conduzido em casa de vegetação, que observaram diferença significativa entre os tratamentos com inoculante padrão e carboxin + tiram + IP, quando comparados ao tratamento carbendazin + tiram + IP (Produto B), que apresentou maior teor de N. Do mesmo modo, Campo et al. (9) observaram, em casa de vegetação, que a nodulação e o $\mathrm{N}$ total acumulado na parte aérea da soja no estádio R2 foram reduzidos em $27 \%$ e $19 \%$, respectivamente.

No segundo experimento conduzido sob condições controladas de casa de vegetação, utilizando-se vasos com substrato (areia e vermiculita) esterilizado, verificou-se que todos os tratamentos de sementes com fungicidas afetaram significativamente $(\mathrm{p}<0,01)$ o número e matéria seca de nódulos, em comparação com as plantas do feijoeiro apenas inoculadas com a mistura das estirpes de $R$. tropici e $R$. freirei. A redução no número de nódulos variou de $16 \%$ (fludioxonil + metalaxil-M) até 50\% (carbendazim + tiram - Produto B), quando comparadas com as plantas somente inoculadas (Tabela 4). Quanto à produção de matéria seca de nódulos, a redução variou de $15 \%$ a $40 \%$, pela aplicação dos fungicidas com fludioxonil + metalaxil-M e carbendazim + tiram (Produto B), respectivamente. Resultados similares foram observados por Mercante et al. (28), onde o número e matéria seca de nódulos reduziram entre $77 \%$ e $96 \%$ com a aplicação dos fungicidas captan, carbendazim + tiram, tiram e carboxim + tiram.

Quanto à produção de matéria seca da parte aérea das plantas, verificou-se um incremento pela aplicação dos fungicidas fludioxonil + metalaxil-M e fludioxonil + metalaxil-M + tiabendazol, quando comparado ao tratamento que recebeu apenas a inoculação de rizóbio, sem aplicação de fungicidas (Tabela 4). Os fungicidas carboxim + tiram e fluazinam + tiofanato metílico afetaram significativamente a produção de matéria seca da parte aérea do feijoeiro, enquanto os demais produtos foram similares $(\mathrm{P}<0,01)$ à aplicação do inoculante, isento de fungicidas (Tabela 4). Experimentos conduzidos por Balardin et al. (6) demonstraram que o efeito do tratamento de sementes favoreceu o crescimento radicular, influenciando a absorção de água,

Tabela 3. Efeito da inoculação e do tratamento de sementes de feijoeiro (cultivar Pérola) com fungicidas, sobre o número de nódulos, matéria seca de nódulos, matéria seca da parte aérea e nitrogênio total da parte aérea das plantas, em ensaio conduzido em casa de vegetação (vasos de Leonard).

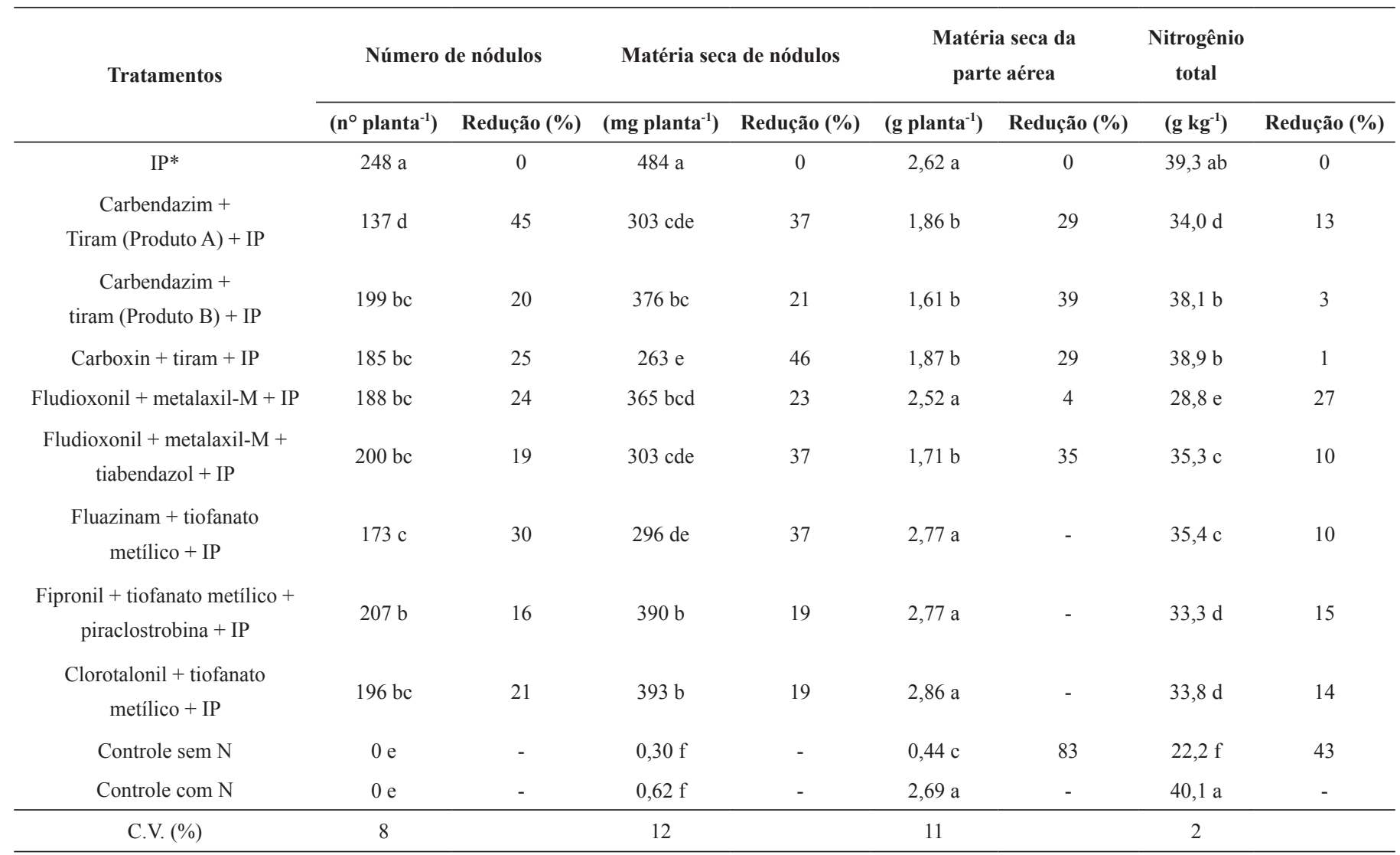

Médias seguidas por letras distintas, na coluna, diferem entre si pelo teste de Tukey, a 1\% de probabilidade.

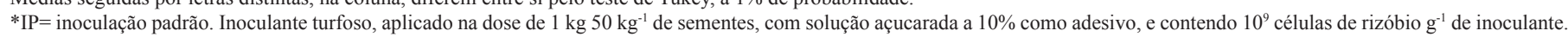


nutrientes e minimizando a redução de área foliar. Além disso, diversos trabalhos têm demonstrado a influência das estrobilurinas, neste caso a piraclostrobina, na melhoria do crescimento vegetal. Resultados obtidos por Balardin et al. (6) demonstraram que o crescimento da parte aérea foi aumentado pelo tratamento de sementes com piraclostrobina + tiofanato metílico + fipronil.

Os teores de $\mathrm{N}$ total da parte aérea dos feijoeiros não foram afetados pelo uso dos diferentes fungicidas no tratamento das sementes. Os teores de $\mathrm{N}$ da parte aérea mais elevados foram verificados no tratamento com $\mathrm{N}$ mineral, sem aplicação de fungicidas, não diferindo, contudo, da maioria dos tratamentos com aplicação de fungicidas e do tratamento onde houve somente a inoculação com rizóbio (Tabela 4).

\section{Ensaio conduzido no campo}

De modo geral, verificou-se um efeito prejudicial dos fungicidas na nodulação (massa seca de nódulos) das plantas de feijoeiro, embora numericamente não tenha sido detectada diferença $(p<0,01)$ em relação ao tratamento que recebeu inoculação com rizóbios, sem aplicação de fungicida, exceto para a aplicação de fipronil + tiofanato metílico + piraclostrobina. A redução do número de nódulos variou de $21 \%$ (fluazinam + tiofanato metílico) a 57\% (fipronil + tiofanato metílico + piraclostrobina + IP), em comparação com as plantas apenas inoculadas com as estirpes de rizóbio, sem tratamento prévio das sementes com fungicidas (Tabela 5). Quanto à produção da matéria seca de nódulos, os tratamentos com aplicação dos fungicidas carboxin + tiram e fludioxonil + metalaxil-M promoveram as reduções mais expressivas ( $83,6 \%$ e $84 \%$, respectivamente), quando comparados com as plantas de feijoeiro apenas inoculadas com os rizóbios. Resultados experimentais obtidos por Araújo \& Araújo (3), em condições controladas de casa de vegetação, demonstraram que, nos tratamentos com a utilização de tiram, houve uma diminuição no número e na matéria seca de nódulos, enquanto os tratamentos com carboxin + tiram também apresentaram uma diminuição na matéria seca de nódulos, quando comparados ao tratamento somente com a inoculação de estirpes de rizóbio. Em estudos conduzidos a campo com a cultura da soja, Campo et al. (9) verificaram que, em geral, todos os fungicidas testados (contato e/ou sistêmico) apresentaram algum grau de toxicidade para as bactérias inoculadas nodulantes da soja, refletindo numa redução da nodulação, quando comparado com o tratamento onde as sementes foram apenas inoculadas. Contudo, estes autores observaram que os efeitos são mais drásticos em áreas de primeiro cultivo de soja. Em outros estudos, foi observado que a inoculação de estirpes de Bradyrhizobium japonicum, quando realizada em aplicação no sulco de semeadura, minimizou os efeitos negativos na nodulação da soja e na produtividade da cultura pelo tratamento das sementes com os fungicidas (10).

A produção de matéria seca da parte aérea foi afetada negativamente pela aplicação dos fungicidas carbendazim + tiram (Produto B), fludioxonil + metalaxil-M + tiabendazol, fluazinam + tiofanato metílico,

Tabela 4. Efeito da inoculação e do tratamento de sementes de feijoeiro (cultivar Pérola) com fungicidas, sobre o número de nódulos, matéria seca de nódulos, matéria seca da parte aérea e nitrogênio total da parte aérea das plantas, em ensaio conduzido em casa de vegetação (vasos de $500 \mathrm{~mL}$ ).

\begin{tabular}{|c|c|c|c|c|c|c|c|c|}
\hline \multirow{2}{*}{ Tratamentos } & \multicolumn{2}{|c|}{ Número de nódulos } & \multicolumn{2}{|c|}{ Matéria seca de nódulos } & \multirow{2}{*}{$\begin{array}{c}\begin{array}{c}\text { Matéria seca da } \\
\text { parte aérea }\end{array} \\
\left(\text { g planta }^{-1}\right)\end{array}$} & \multicolumn{3}{|c|}{$\begin{array}{l}\text { Nitrogênio } \\
\text { total }\end{array}$} \\
\hline & $\begin{array}{c}\left(n^{\circ}\right. \\
\left.\text { planta }^{-1}\right)\end{array}$ & $\begin{array}{c}\text { Redução } \\
(\%)\end{array}$ & $\begin{array}{c}(\mathrm{mg} \\
\left.\text { planta }^{-1}\right)\end{array}$ & $\begin{array}{c}\text { Redução } \\
(\%)\end{array}$ & & $\begin{array}{c}\text { Redução } \\
(\%)\end{array}$ & $\left(\mathrm{g} \mathrm{kg}^{-1}\right)$ & $\begin{array}{c}\text { Redução } \\
(\%)\end{array}$ \\
\hline IP & $150 \mathrm{a}$ & 0 & $203 \mathrm{a}$ & 0 & $1,72 \mathrm{bcd}$ & 0 & $31,3 \mathrm{ab}$ & 0 \\
\hline $\begin{array}{c}\text { Carbendazim }+ \\
\text { tiram (Produto A) + IP }\end{array}$ & 96 cde & 36 & $153 \mathrm{bc}$ & 25 & $1,65 \mathrm{de}$ & 4 & $32,0 \mathrm{ab}$ & - \\
\hline $\begin{array}{c}\text { Carbendazim }+ \\
\text { tiram (Produto B) }+ \text { IP }\end{array}$ & $75 \mathrm{e}$ & 50 & $118 \mathrm{e}$ & 40 & $1,67 \mathrm{cde}$ & 3 & $30,5 \mathrm{ab}$ & 3 \\
\hline Carboxin + tiram + IP & $114 \mathrm{bc}$ & 24 & $159 \mathrm{bc}$ & 20 & $1,62 \mathrm{e}$ & 6 & $30,9 \mathrm{ab}$ & 2 \\
\hline Fludioxonil + Metalaxil-M + IP & $126 \mathrm{~b}$ & 16 & $170 \mathrm{~b}$ & 15 & $1,85 \mathrm{a}$ & - & $27,9 \mathrm{ab}$ & 11 \\
\hline $\begin{array}{c}\text { Fludioxonil + Metalaxil-M + } \\
\text { Tiabendazol + IP }\end{array}$ & 82 de & 45 & $145 \mathrm{~cd}$ & 25 & $1,85 \mathrm{a}$ & - & $26,88 \mathrm{ab}$ & 14 \\
\hline $\begin{array}{c}\text { Fluazinam + Tiofanato } \\
\text { metílico }+ \text { IP }\end{array}$ & $104 \mathrm{bcd}$ & 31 & $128 \mathrm{de}$ & 35 & $1,59 \mathrm{e}$ & 8 & $32,2 \mathrm{ab}$ & - \\
\hline $\begin{array}{c}\text { Fipronil + Tiofanato metílico }+ \\
\text { Piraclostrobin + IP }\end{array}$ & $117 \mathrm{bc}$ & 22 & $155 \mathrm{bc}$ & 20 & $1,80 \mathrm{ab}$ & - & $29,3 \mathrm{ab}$ & 6 \\
\hline $\begin{array}{c}\text { Clorotalonil + Tiofanato } \\
\text { metílico + IP }\end{array}$ & $114 \mathrm{bc}$ & 24 & $162 \mathrm{bc}$ & 20 & $1,75 \mathrm{abc}$ & - & $24,4 b$ & 22 \\
\hline Controle sem N & $0 \mathrm{f}$ & - & $0 \mathrm{f}$ & - & $1,34 \mathrm{f}$ & 22 & $25,6 \mathrm{~b}$ & 18 \\
\hline Controle com N & $0 \mathrm{f}$ & - & $0 \mathrm{f}$ & - & $1,82 \mathrm{ab}$ & - & $34,3 \mathrm{a}$ & - \\
\hline C.V. $(\%)$ & 12 & & 7 & & 2 & & 8 & \\
\hline
\end{tabular}

Médias seguidas por letras distintas, na coluna, diferem entre si pelo teste de Tukey, a $1 \%$ de probabilidade.

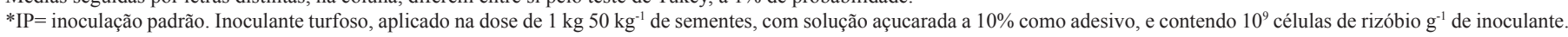


fipronil + tiofanato metílico + piraclostrobina e clorotalonil + tiofanato metílico, associado à aplicação do inoculante, quando comparada com o tratamento que recebeu apenas a inoculação das estirpes de rizóbio. Estudos realizados por Araújo et al. (4), em condições de campo, mostraram que não houve alteração significativa na produção de matéria seca da parte aérea das plantas de feijoeiro, comparando as plantas tratadas com carbendazin + IP e aquelas somente inoculadas com rizóbio.

Os teores de $\mathrm{N}$ na parte aérea das plantas situaram-se entre 38 e $45 \mathrm{~g} \mathrm{~kg}^{-1}$, sendo estes valores considerados satisfatórios para o desempenho da cultura do feijoeiro (32). No presente estudo, verificouse que o tratamento correspondente à adubação mineral nitrogenada promoveu teores similares $(\mathrm{p}<0,01)$ de $\mathrm{N}$ total na parte aérea, quando comparado com as plantas que receberam apenas a inoculação (Tabela 5). Araújo et al. (4) verificaram que a inoculação de sementes tem a mesma capacidade de incorporação de nitrogênio às plantas, quando comparado à adição de nitrogênio na forma mineral. Os fungicidas com os princípios ativos carboxin + tiram, fludioxonil + Metalaxil-M, fipronil + tiofanato metílico + piraclostrobina e clorotalonil + tiofanato metílico foram os que mais reduziram o acúmulo de $\mathrm{N}$ na parte aérea das plantas de feijoeiro (Tabela 5).

A maioria dos fungicidas avaliados afetou a produtividade da cultura do feijoeiro. Contudo, os tratamentos com aplicação dos fungicidas com os princípios ativos fipronil + tiofanato metílico + piraciostrobina, fludioxonil + metalaxil-M + tiabendazol e fludioxonil + metalaxil-M proporcionaram rendimentos de grãos similares $(\mathrm{p}<0,01)$ ao tratamento que recebeu apenas a inoculação padrão com rizóbio (Tabela 5). O rendimento de grãos pela utilização do tratamento com fipronil + tiofanato metílico + piraclostrobina + IP foi superior aos demais tratamentos com aplicação de fungicidas.

Os tratamentos com a aplicação de carbendazim + tiram (Produto B) e carboxin + tiram apresentaram menor produtividade, com uma redução de $18,4 \%$ e $26,2 \%$, respectivamente, em comparação ao tratamento somente inoculado com rizóbio. Revellin et al. (36) verificaram, em cultivo a campo de soja, que, embora a aplicação de carboxin + tiram + IP tenha reduzido significativamente o número e matéria seca de nódulos em relação à inoculação padrão, a produtividade da cultura não foi afetada. Estudos realizados por Balardin et al. (6) mostraram que a utilização de piraclostrobina no tratamento de sementes de soja propiciou aumento significativo na matéria seca de raízes e matéria seca da parte aérea das plantas. Estes autores verificaram que as plantas oriundas de sementes tratadas com fipronil + tiofanato metílico + piraclostrobina tiveram aumento no conteúdo de clorofila. Estas melhorias na fisiologia das plantas, proporcionadas pela utilização de piraclostrobina + fipronil + tiofanato metílico, podem determinar melhorias nas condições da planta em expressar maior capacidade produtiva. Neste contexto, Fagan et al. (16) conduziram estudos no campo e verificaram que a aplicação de piraclostrobina ocasionou incremento na taxa fotossintética de plantas tratadas e tiveram um acréscimo de 7\% e 8\% na massa de mil grãos e de 1080 e $468 \mathrm{~kg} \mathrm{ha}^{-1}$ na produtividade, quando comparado à testemunha sem aplicação e o tratamento com triazol (tebuconazol), respectivamente.

Tabela 5. Efeito da inoculação e do tratamento de sementes de feijoeiro (cultivar Pérola) com fungicidas, sobre o número de nódulos, matéria seca de nódulos, matéria seca da parte aérea, nitrogênio total da parte aérea das plantas e produtividade, em ensaio conduzido no campo. Dourados, março - junho, 2012.

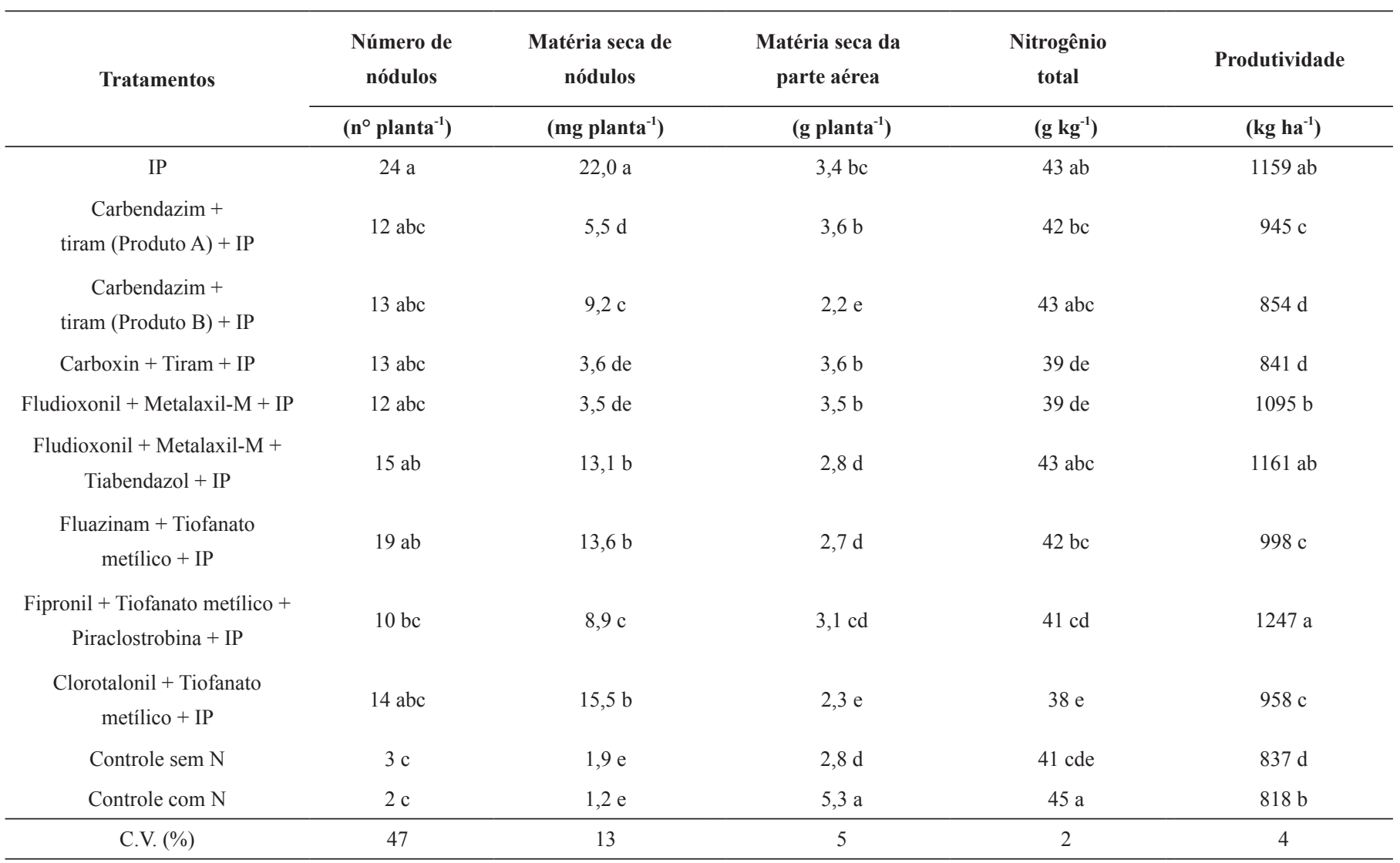

Médias seguidas por letras distintas, na coluna, diferem entre si pelo teste de Tukey, a $1 \%$ de probabilidade.

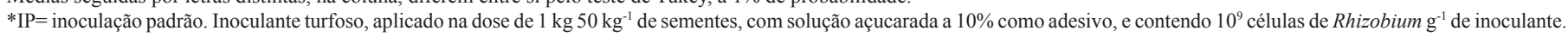


Neste mesmo estudo, os resultados indicaram que a piraclostrobina afetou a taxa de assimilação de carbono e de nitrogênio na cultura da soja, o que refletiu na produtividade de grãos.

Contudo, deve-se salientar que os problemas fitossanitários estão entre os principais problemas que limitam a produtividade da cultura do feijoeiro, uma vez que as perdas anuais de produção são geralmente significativas (34). Neste contexto, a adoção de medidas apropriadas para o controle de doenças, como a utilização de sementes certificadas e de cultivares resistentes, consiste na forma mais eficaz e econômica para evitar a maioria das doenças. Considerando que a maioria dos fungicidas avaliados no presente estudo apresentou, em algum grau de intensidade, um efeito de toxicidade sobre os rizóbios inoculados nas sementes, conduzindo a perdas no rendimento de grãos da cultura, a importância de tais medidas tornam-se ainda mais relevantes.

A sobrevivência das estirpes de rizóbio ( $R$. tropici $+R$. freirei) inoculadas nas sementes de feijoeiro foi afetada pela aplicação dos fungicidas avaliados, principalmente pelos produtos com modo de ação por contato.

De modo geral, a aplicação de fungicidas ocasionou uma redução na nodulação das plantas de feijoeiro, especialmente na massa nodular, tanto nos ensaios conduzidos em substrato esterilizado, em casa de vegetação, quanto no experimento no campo, onde também se observou uma redução na produtividade da cultura pela aplicação da maioria dos fungicidas avaliados.

A aplicação dos fungicidas contendo os princípios ativos fipronil + tiofanato metílico + piraclostrobina, fludioxonil + metalaxil-M + tiabendazol e fludioxonil + metalaxil-M não afetaram a produtividade do feijoeiro, embora tenha afetado a nodulação (matéria seca de nódulos) das plantas. Por outro lado, os fungicidas que mais afetaram o rendimento de grãos da cultura foram carbendazim + tiram (Produto B) e carboxin + tiram.

\section{REFERÊNCIAS BIBLIOGRÁFICAS}

1. Amaral, J.A.M.; Motchi, E.P.; Oliveira, H.; Carvalho Filho, A.; Naime, U.J.; Santos, R.D. Levantamento semidetalhado dos solos do campo experimental de Dourados, da Embrapa Agropecuária Oeste, Município de Dourados, MS. Dourados: Embrapa Agropecuária Oeste, 2000. 68p. (Embrapa Agropecuária Oeste. Documentos, 22; Embrapa Solos. Documentos, 15).

2. Andrade, D.S.; Hamakawa, P.J. Estimativa do número de células viáveis de rizóbio no solo e em inoculantes por infecção em plantas. In: Hungria, M.; Araujo, R.S. (Ed.). Manual de métodos empregados em estudos de microbiologia agrícola. Brasília, DF: Embrapa, 1994. p.63-94.

3. Araújo, A.S.F.; Araújo, R.S. Sobrevivência e nodulação do Rhizobium tropici em sementes de feijão tratadas com fungicidas. Ciência Rural, Santa Maria, RS, v.36, n.3, p.973-976, 2006.

4. Araújo, F.F.; Carmona, F.G.; Tiritan, C.S.; Creste, J.E. Fixação biológica de $\mathrm{N}_{2}$ no feijoeiro submetido a dosagens de inoculante e tratamento químico na semente comparado à adubação nitrogenada. Acta Scientiarum: agronomy, Maringá, v.29, n.4, p.535-540, 2007.

5. Araújo, R.S. Fixação biológica do nitrogênio em feijão. In: Araújo, R.S.; Hungria, M. (Ed.). Microrganismos de importância agrícola. Brasília, DF: EMBRAPA-SPI, 1994. p.91-120.

6. Balardin, R.S.; Silva, F.D.L.; Debona, D.; Corte, G.D.; Favera, D.D.; Tormen, N.R. Tratamento de sementes com fungicidas e inseticidas como redutores dos efeitos do estresse hídrico em plantas de soja. Ciência Rural, Santa Maria, RS, v.41, n.7, p.1120-1126, 2011.

7. Bigaton, D.; Bacchi, L.M.A.; Mercante, F.M.; Gavassoni, W.L. Fungicidas aplicados em tratamento de sementes de soja e seus efeitos sobre a nodulação e a fixação biológica de nitrogênio. Revista Agricultura Tropical, Cuiabá, v.9, p.87-101, 2006.

8. Campo, R.J.; Araujo, R.S.; Hungria, M. Nitrogen fixation with the soybean crop in Brazil: compatibility between seed treatment with fungicides and bradyrhizobial inoculants. Symbiosis, Dordrecht, v.48, n.1/3, p.154-163, 2009.

9. Campo, R.J.; Araujo, R.S.; Mostasso, F.L.; Hungria, M. In-furrow inoculation of soybean as alternative to fungicide and micronutrient seed treatment. Revista Brasileira de Ciência do Solo, Viçosa, MG, v.34, n.6, p.1103-1112, 2010.

10. Campo, R.J.; Hungria, M. Compatibilidade de uso de inoculantes e fungicidas no tratamento de sementes de soja. Londrina: Embrapa Soja, 2000. 32p. (Embrapa Soja. Circular técnica, 26).

11. Canteri, M.G.; Dalla Pria, M.; Silva, O.C. (Ed.). Principais doenças fúngicas do feijoeiro: orientações para manejo econômico e ecológico. Ponta Grossa: UEPG, 1999. 178p.

12. Cattelan, A.J.; Spoladori, C.L.; Henning, A.A. Efeito do tratamento de sementes de soja com fungicidas recomendados sobre a fixação do nitrogênio atmosférico e a sobrevivência do Bradyrhizobium japonicum em casa de vegetação. In: Simpósio Brasileiro sobre Microbiologia do Solo, 3.; Reunião de Laboratórios para Recomendação de Estirpes de Rhizobium e Bradyrhizobium, 6., 1994, Londrina. Microbiologia do solo: desafios para o século XXI - anais. Londrina: IAPAR: EMBRAPA-CNPSo, 1995. p.399-403.

13. Conab. Acompanhamento da safra brasileira: grãos: safra 2011/2012: nono levantamento junho 2012. Brasília, DF, 2012. Disponível em: $<$ http://www. conab.gov.br/OlalaCMS/uploads/arquivos/12_06_05_09_50_17_boletim_safra_-junho-2012.pdf $>$. Acesso em: 25 set. 2012.

14. Costa, M.R.; Kawski, N.L.; Gil, F.K.U.; Goulart, A.C.P.; Mercante, F.M. Aplicação de fungicidas em sementes de soja e seus efeitos na nodulação e fixação biológica de nitrogênio. In: Reunião Brasileira de Fertilidade do Solo e Nutrição de Plantas, 27.; Reunião Brasileira sobre Micorrizas, 11.; Simpósio Brasileiro de Microbiologia do Solo, 9.; Reunião Brasileira de Biologia do Solo, 6., 2006, Bonito, MS. A busca das raízes: anais. Dourados: Embrapa Agropecuária Oeste, 2006. 1 CD-ROM. (Embrapa Agropecuária Oeste. Documentos, 82).

15. Duque, F.F.; Neves, M.C.P.; Franco, A.A.; Victoria, R.L.; Boddey, R.M. The response of field grown P. vulgaris to Rhizobium inoculation and qualification of N fixation using ${ }^{15} \mathrm{~N}$. Plant and Soil, Dordrecht, v.88, n.1, p.333-343, 1985 .

16. Fagan, E.B.; Dourado Neto, D.; Vivian, R.; Franco, R.B.; Yeda, M.P.; Massignam, L.F.; Oliveira, R.F.; Martins, K.V. Efeito da aplicação de piraclostrobina na taxa fotossintética, respiração, atividade da enzima nitrato redutase e produtividade de grãos de soja. Bragantia, Campinas, v.69, n.4, p.771-777, 2010.

17. Goulart, A.C.P. Doenças do feijoeiro na região norte de Minas Gerais. Fitopatologia Brasileira, Brasília, DF, v.13, n.3, p.230-232, 1988.

18. Goulart, A.C.P. Efeito do tratamento de sementes de feijão (Phaseolus vulgaris L.) com fungicidas para o controle de Colletotrichum lindemuthianum $\mathrm{e}$ Rhizoctonia solani. Ciência e Prática, Lavras, v.16, n.2, p.214-218, 1992.

19. Hungria, M.; Andrade, D.S.; Chueire, L.M.O.; Probanza, A.; GuttierrezMañero, F.J.; Megías, M. Isolation and characterization of new efficient and competitive bean (Phaseolus vulgaris L.) rhizobia from Brazil. Soil Biology and Biochemistry, Oxford, v.32, n.11/12, p.1515-1528, 2000.

20. Hungria, M.; Araújo, R.S. Manual de métodos empregados em estudos de microbiologia agrícola. Brasília, DF: EMBRAPA; Santo Antônio de Goiás: EMBRAPA-CNPAF; Londrina: EMBRAPA-CNPSo, 1994. 542p. (EMBRAPA-CNPAF. Documentos, 42).

21. Hungria, M.; Campo, R.J.; Mendes, I.C. A importância do processo de fixação biológica do nitrogênio para a cultura da soja: componente essencial para a competitividade do produto brasileiro. Londrina: Embrapa Soja, 2007. 80p.

22. Hungria, M.; Vargas, M.A.T.; Araújo, R.S. Fixação biológica do nitrogênio em feijoeiro. In: Vargas, M.A.T.; Hungria, M. (Ed.). Biologia dos solos dos Cerrados. Brasília, DF: Embrapa Cerrados, 1997. cap.5, p.187-258.

23. Machado, J.C.; Langerak, C.J.; Jaccoud-Filho, D.S. Seed-borne fungi: a contribution to routine seed health analysis. Bassersdorf: ISTA, 2002.138p.

24. Malavolta, E.; Vitti, G.C.; Oliveira, S.A. Avaliação do estado nutricional das plantas: princípios e aplicações. Piracicaba: POTAFOS, 1997. 201p.

25. Martínez-Romero, E.; Segovia, E.; Mercante, F.M.; Franco, A.A.; Graham, P.H.; Pardo, M.A. Rhizobium tropici, a novel species nodulating Phaseolus vulgaris L. beans and Leucaena sp. trees. International Journal of Systematic Bacteriology, Washington, DC, v.41, n.3, p.417-426, 1991.

26. Mercante, F.M. Uso de Leucaena leucocephala na obtenção de Rhizobium tolerante a temperatura elevada para inoculação do feijoeiro. 
1993. 149p. Dissertação (Mestrado em Agronomia, área de concentração em Ciência do Solo) - Universidade Federal Rural do Rio de Janeiro, Seropédica.

27. Mercante, F.M.; Costa, M.R.; Kawski, N.L.; Tarasiuk, V.A.; Goulart, A.C.P. Sobrevivência de Bradyrhizobium spp em sementes de soja tratadas com fungicidas e seus efeitos na nodulação das plantas. In: Congresso Brasileiro de Ciência do Solo, 31., 2007, Gramado. Microbiologia do solo: conquistas e desafios para a ciência do solo. [Porto Alegre]: UFRGS Solos: SBCS, Núcleo Regional Sul, 2007. 1 CD-ROM.

28. Mercante, F.M; Moretto, H.J.N.; Tarasiuk, V.A.; Goulart, A.C.P. Efeitos de fungicidas na nodulação de feijoeiros inoculados com Rhizobium tropici. In: Reunião da Rede de Laboratórios para Recomendação, Padronização e Difusão de Tecnologia de Inoculantes Microbiológicos de Interesse Agrícola, 14., 2010, Bonito, MS. Anais... Dourados: Embrapa Agropecuária Oeste, 2010. p. $50-51$

29. Neergaard, P. Seed pathology. London: Macmillan Press, 1977. 839p.

30. Norris, D.O.; T'Mannetje, L. The symbiotic specialization of African Trifolium spp. in relation to their taxonomy and their agronomic use. East African Agricultural and Forestry Journal, Nairobi, v.29, n.2, p.214-35, 1964.

31. Oliveira, P.P.A.; Tsai, S.M.; Corsi, M.; Díaz, M.D.P. Interação entre cultivares, estirpes comerciais de Rhizobium meliloti e fungicidas no incremento da produção de alfafa. Pesquisa Agropecuária Brasileira, Brasília, DF, v.34, n.3, p.425-431, 1999.

32. Oliveira, S.A.D.; Thung, M.R.T. Nutrição mineral. In: Zimmermann, M.J.O.; Rocha, M.; Yamada, T. Cultura do feijoeiro: fatores que afetam a produtividade. Piracicaba: Associação Brasileira para a Pesquisa da Potassa e do Fosfato, 1988. p.175-212.

33. Pelegrin, R.; Mercante, F.M.; Otsubo, I.M.N.; Otsubo, A.A. Resposta da cultura do feijoeiro à adubação nitrogenada e à inoculação com rizóbio. Revista Brasileira de Ciência do Solo, Viçosa, MG, v.33, n.1, p.219-226, 2009.

34. Posse, S.C.P.; Riva-Souza, E.M.; Silva, G.M.; Fasolo, L.M.; Silva, M.B.; Rocha, M.A.M. Informações técnicas para o cultivo do feijoeiro-comum na região central-brasileira: 2009-2011. Vitória: Incaper, 2010. 245p.
(Incaper. Documentos, 191).

35. Ramos, M.L.G.; Ribeiro Júnior, W.Q. Effect of fungicide on survival of Rhizobium on seeds and the nodulation of bean (Phaseolus vulgaris L.). Plant and Soil, Dordrecht, v.152, n.1, p.145-150, 1993.

35. Revellin, C.; Leterme, P.; Catroux, G. Effect of some fungicide seed treatment on the survival of Bradyrhizobium japonicum and nodulation and yield of soybean [Glycine max (L.) Merr.]. Biology and Fertility of Soils, Berlin, v.16, n.3, p.211-214, 1993.

36. Richardson, M.S. An annoted list of seed borne diseases. 3.ed. Kew: CAB: CMI; Zurich: ISTA, 1979. 320p. (Phytopathological papers, 23).

37. Sartorato, A. Antracnose. In: Zimmermann, M.J.; Rocha, M.; Yamada, T. Cultura do feijoeiro: fatores que afetam a produtividade. Goiânia: Associação Brasileira para a Pesquisa de Potassa e de Fósforo, 1988. p.457-477.

38. Silva, F.A.S.; Azevedo, C.A.V. Versão do programa computacional Assistat para o sistema operacional Windows. Revista Brasileira de Produtos Agroindustriais, Campina Grande, v.4, n.1, p.71-78, 2002.

39. Straliotto, R.; Teixeira, M.G.; Mercante, F.M. Fixação biológica de nitrogênio. In: Aidar, H.; Kluthcouski, J.; Stone, L.F. (Ed.). Produção de feijoeiro comum em várzeas tropicais. Santo Antônio de Goiás: Embrapa Arroz e Feijão, 2002. p.122-153.

40. Suhet, A.R.; Peres, J.R.R.; Vargas, M.A.T. Nitrogênio. In: Goedert, W.J. (Ed.). Solos dos Cerrados: tecnologias e estratégias de manejo. Planaltina, DF: EMBRAPA-CPAC; São Paulo: Nobel, 1986. p.167-202.

41. Vieira, C. Adubação mineral e calagem. In: Vieira, C.; Paula Junior, T.J.; Borém, A. (Ed.). Feijão: aspectos gerais e cultura no Estado de Minas. Viçosa, MG: Universidade Federal de Viçosa, 1998. p.123-152.

42. Vincent, J.M. A manual for the practical study of root nodule bacteria. London: International Biological Programme, 1970. 164p. (IBP handbook, 15).

43. Yokoyama, L.P. Aspectos conjunturais da produção de feijão. In: Aidar, H.; Kluthcouski, J.; Stone, L.F. (Ed.). Produção de feijoeiro comum em várzeas tropicais. Santo Antônio de Goiás: Embrapa Arroz e Feijão, 2002. p.249-292. 